\title{
A ORGANIZAÇÃO DO TRABALHO NA ASSISTÊNCIA AO RECÉM-NASCIDO EM BERÇÁRIOS DA REGIONAL DE RIBEIRÃO PRETO-SP. BRASIL-1992
}

\author{
Carmen Gracinda Silvan Scochi* \\ Emília Luigia Saporiti Angerarni ** \\ Semiramis Melani Melo Rocha* \\ Regina Aparecida Garcia de Lima*
}

\begin{abstract}
SCOCHI, C.G.S.; ANGERAMI, E.L.S.; ROCHA, S.M.M.; LIMA, R.A.G.de. A organização do trabalho na assistência ao recém-nascido em berçários da regional de Ribeirão Preto-SP. Brasil - 1992. Rev.latino-am.enfermagem, Ribeirão Preto, v. 5, n. 1, p. 27-36, janeiro 1997.
\end{abstract}

\begin{abstract}
O estudo analisa a organização da assistência ao recém-nascido em berçários da regional de Ribeirão Preto e a participação da enfermagem neste trabalho. Através de observação e entrevistas em quatro berçários, constata-se que a organização do trabalho diferencia-se pelo porte e complexidade do hospital. A ação está centrada na criança e nos casos mais complexos prioriza -se a patologia e a assistência clínica. Percebe-se também, algumas ações mais amplas, apreendendo o binômio mãe-filho e a família. $O$ nível de atenção é resultado de uma complexa combinação dos recursos humanos, materiais e área física. A instituição de maior porte e complexidade apresenta diversidade de agentes, trabalho mais burocratizado e hierarquizado, sistema de informação e tecnologias complexas, procedimentos rotinizados mediados por normas escritas e aparelhos sofisticados. O objeto de ação está centrado na criança, mas há práticas cujo objeto é ampliado para o binômio mãe-filho e familiares.
\end{abstract}

UNITERMOS: assistência neonatal, berçários, enfermagem neonatal

\section{INTRODUÇÃO}

Os coeficientes de mortalidade infantil e neonatal, no Brasil, são bastante elevados, mesmo considerando a série histórica decrescente ao longo do tempo. No período entre 1985 e 1990, a modalidade infantil foi da ordem de 63 por 1000 nascidos vivos, sendo estimada em 48 por 1000 nascidos vivos para o ano 2000. O decréscimo que tem ocorrido deve-se, sobretudo, à redução do componente pós-natal, pois o neonatal passou a ser maior em termos proporcionais, embora também tenha decrescido. Em 1986, as afecções perinatais representaram 45\% da mortalidade infantil $^{1}$, destacando-se, dentre as causas, a anóxia, traumas obstétricos, prematuridade, desnutrição intrauterina, malformações congênitas e infecções.

No município de Ribeirão Preto, Estado de São Paulo, o coeficiente neonatal diminuiu de 18,7 em 1980 para 12,6 por 1000 nascidos vivos, em 1991, representando mais de $64 \%$ da mortalidade infantil ${ }^{2}$. Estas taxas são altas se comparadas aos países desenvolvidos. As perdas fetais e neonatais não reduziram na mesma proporção em relação à mortalidade geral devido a suas raízes em desequilíbrios da organização médico-sanitária e sócio-econômica. Entre as recomendações apontadas para melhorar estes indicadores destaca-se a organização de serviços de saúde para atendimento ao pré-natal, parto e ao recém-nascido.

As primeiras instalações de berçário, no Brasil, surgiram em 1945, passando por várias transformações. $\mathrm{Na}$ década de 70, especialistas e órgãos governamentais mobilizaram-se estabelecendo diretrizes e normas técnicas para sua organização e padronização. Na década de 80 , foi incorporado às normas técnicas o novo conceito de unidades de atendimento por níveis de complexidade, através de uma rede regional hospitalar organizada em três níveis de cuidado. O processo político-institucional e administrativo de reestruturação do sistema de saúde, desencadeado nessa década, envolveu várias propostas e estratégias para a expansão de cobertura dos serviços, destacando-se: a formulação e implantação das Ações Integradas de Saúde (AIS) em 1983; as mudanças institucionais decorrentes dos princípios básicos estabelecidos na $8^{a}$ Conferência Nacional de Saúde, em 1986; a Constituição promulgada em 1988, onde o direito à saúde tornou-se um preceito e obrigação do Estado assegurá-lo; a implantação do Sistema Único de Saúde (SUS), com a unificação e descentralização dos serviços, através do Sistema Unificado e Descentralizado de

\footnotetext{
* Docentes do Departamento de Enfermagem Materno-Infantil e Saúde Pública da Escola de Enfermagem de Ribeirão Preto da Universidade de São Paulo. Grupo de Estudos em Saúde da Criança e do Adolescente

** Professora Titular Aposentada do Departamento de Enfermagem Geral e Especializada da Escola de Enfermagem de Ribeirão Preto da Universidade de São Paulo
} 
Saúde (SUDS), em 1987, cujo programa contribuiu para a consolidação e desenvolvimento das AIS. Essas transformações culminaram no processo de Municipalização da Saúde.

No que se refere à atenção ao parto e recémnascido, estabeleceram-se programas visando à extensão da cobertura da assistência hospitalar, utilizando o enfoque de risco. Posteriormente, surgiram propostas racionalizadoras recomendando 0 estabelecimento de centros de referência ambulatorial e hospitalar, dentro de uma rede regionalizada e hierarquizada por nível de complexidade crescente. As normas técnicas, emergentes a partir da década de 80 , continham diretrizes para a organização dos serviços de saúde perinatal em três níveis, de acordo com a complexidade do cuidado executado em cada hospital, definida pela disponibilidade de recursos humanos e tecnológicos.

Em Ribeirão Preto, projetou-se o Sistema de Regionalização e Hierarquização no Plano de Saúde de 1989-90, explicitando os serviços nos três níveis de atenção - primário, secundário e terciário - e o fluxograma definindo o referenciamento de casos, exames e a contra-referência ${ }^{3,4}$. Neste estudo, detivemonos na organização da assistência neonatal hospitalar.

Compreender a organização do trabalho em berçários, nesse processo de transformação dos serviços de saúde, em realidades concretas, possibilitará uma assistência de enfermagem de qualidade, de acordo com as condições dos serviços e as necessidades da clientela. Assim, desenvolvemos o presente estudo, tendo como objetivos:

-analisara organização do processo de trabalho na assistência ao recém-nascido em diferentes berçários da regional de Ribeirão Preto, frente à proposta de regionalização e hierarquização do sistema de saúde e às normas e recomendações de unidades de atendimento por níveis de complexidade crescente;

-analisar como a enfermagem se insere $e$ participa desse trabalho.

\section{MATERIAL E MÉTODO}

A organização tecnológica do trabalho é entendida como um processo constituído por saberes e equipamentos em suas formas socialmente determinadas que articulam seus agentes à dinâmica da produção e reprodução social ${ }^{5}$.

Os serviços de saúde são tomados como unidades de observação e análise por se constituírem em lugares estruturais de produção de assistência, onde se reúnem profissionais, saberes, tecnologia e infraestrutura e onde se configuram relações sociais.
Fundamentados neste referencial, construímos os seguintes pressupostos teóricos:

1 - A organização do trabalho diferencia-se pelo porte e complexidade do hospital.

2 - A assistência ao recém-nascido se institucionaliza no espaço hospitalar, local da prática médica do pediatra ou neonatologista, responsável pelo diagnóstico e terapêutica, cabendo à enfermagem neonatal o cuidado direto do neonato e o controle do ambiente do berçário.

3 - O objeto de ação das práticas de saúde em berçário é o corpo anátomo-biológico do neonato em sua adaptação à vida extra-uterina.

4 - As finalidades do trabalho são: a manutenção e restauração das condições de vitalidade do recémnascido, a prevenção de infecções e a diminuição da morbimortalidade.

Os princípios da regionalização dos serviços de saúde perinatal, descritos pela AMERICAN ACADEMY OF PEDIATRICS ${ }^{6}$, constituíram-se em diretrizes para o estabelecimento dos sistemas regionais, sendo recomendados pela Secretaria de Estado da Saúde ${ }^{7}$ e Ministério da Saúde ${ }^{8}$. Indicam a organização da rede em três níveis, de acordo com a complexidade do cuidado executado em cada hospital.

- Nível I - oferecem basicamente serviços a mães e recém-nascidos sem complicações ou com complicações menores. Devem estar capacitados para executar cuidados emergenciais ou de urgência, enquanto prepara-se a imediata transferência do neonato para um hospital de nível II ou III.

- Nível II - proporcionam serviços a mães e neonatos que não apresentam complicações para a maioria dos problemas obstétricos e atendem certos tipos de enfermidades neonatais definidas quer pela disponibilidade de especialistas quer pela concentração de pessoal habilitado no cuidado perinatal. Incluem no atendimento medidas de ressuscitação e ventilação assistida por curto período de tempo ou em algumas unidades até por períodos prolongados.

- Nível III - prestam cuidado intensivo contínuo e constante por muito tempo, dispondo de profissionais em subespecialidades. Exercem a função de centros regionais, devendo realizar programas educacionais, serviços de assessoria e auxílio aos hospitais de níveis 1 e II, dispondo para tanto de pessoal adequado e treinado, que também assume a responsabilidade da comunicação com pais, equipe de saúde e hospitais de sua região.

A pesquisa foi realizada na regional de saúde de Ribeirão Preto, onde existem 27 hospitais com berçários, categorizados em hospitais de pequeno (05), médio (17), grande (04) e porte especial (01), de acordo com a classificação do Ministério da Saúde ${ }^{9} \mathrm{Em}$ cada categoria, sorteamos um berçário denominando-os $A$, $B, C$ e D, localizados nos municípios de Santa Rosa de Viterbo (A), Jaboticabal (B) e Ribeirão Preto (C e D). 
Os dados foram coletados no período entre janeiro a outubro de 1992, através das técnicas de observação e entrevista. Em cada instituição fizemos uma entrevista semi-estruturada com a enfermeira ou responsável pelo serviço de enfermagem e outra com o chefe do berçário, para situar a unidade dentro da estrutura hospitalar, dimensionar os recursos humanos, a dinâmica do trabalho, distribuição do pessoal e as normas de serviço.

As entrevistas realizadas tinham a finalidade de quantificar e qualificar dados importantes, completando as informações obtidas em outras fontes como censos e estatísticas das instituições, cujo mapeamento possibilitou também, um direcionamento das observações.

Realizamos a observação não-participante em diferentes períodos do dia, a fim de verificar a dinâmica do trabalho em diferentes plantões, registrando-se os dados em um Diário de Campo, sob a forma de relato cursivo. Foi complementada pela observação controlada sistemática, orientada por roteiros e um formulário baseado no guia de avaliação dos serviços de neonatologia da OPAS/OMS ${ }^{10}$.

A análise e a interpretação dos dados foram fundamentadas em passos operacionais propostos por MINAYO ${ }^{11}$. O primeiro consiste numa ordenação dos dados através da leitura e organização do material coletado nas observações, entrevistas e levantamento de cadastros, censos e estatísticas das instituições, delineando um mapa horizontal das descobertas, de acordo com a proposta analítica. No segundo passo, classificamos os dados, após releitura exaustiva do material empírico visando à apreensão das idéias centrais, o confronto e o estabelecimento de relações entre os aspectos observados e o embasamento teórico que fundamenta a investigação. Esta etapa, juntamente com a análise final, constituíram-se em estudo transversal dos quatro berçários, onde procuramos apreender, dentro da dinâmica do trabalho, as atividades desempenhadas pelos diversos agentes, o objeto de ação, os recursos disponíveis, a divisão, instrumentos e finalidades do trabalho, as formas de controle, as relações sociais e de poder que se estabelecem.

\section{RESULTADOS E DISCUSSÃO}

Quadro 1 (em anexo) sintetiza as características dos quatro berçários de acordo com sua classificação, número de leitos e nascimentos, planta física e recursos humanos. Analisando-o, verificamos que os berçários estão inseridos dentro de hospitais heterogêneos do ponto de vista de sua especialidade, estrutura física, entidade mantenedora e uso para ensino. O berçário A é financiado basicamente pela previdência social pública, através de convênios com o SUS; o $D$, pelo governo do Estado de São Paulo. Os berçários B e C atendem, especialmente, clientes particulares e da empresa médica privada.

Há ociosidade na ocupação dos leitos neonatais em três berçários: no A e B, em 1991, a média não chegou a um nascimento por dia, e no $C$ atingiu cerca de três. Por outro lado, o berçário $\mathrm{D}$ recebe, em média, 8 crianças por dia nascidas na própria instituição e ainda interna neonatos de risco advindos de outros hospitais, por constituir-se em centro de referência ambulatorial e hospitalar regional.

A falta de critérios regionais de contra-referência faz com que esses recém-nascidos não sejam encaminhados para berçários de menor complexidade ao término de sua fase crítica, prolongando sua internação. Conseqüentemente utilizam leitos excedentes para atender à demanda desencadeando, ainda, uma sobrecarga de serviço para os profissionais de saúde.

Quanto às instalações físicas, na maioria dos berçários não observamos o cumprimento das recomendações técnicas vigentes ${ }^{6,7,8}$. Não há áreas específicas para o cuidado progressivo, combinando-se um ou mais níveis de complexidade em uma mesma área; o alojamento conjunto não está implantado em todos os serviços. Salas para isolamento e cuidado intensivo foram encontradas em dois berçários. No $\mathrm{C}$, há um único respirador infantil e monitor cardíaco, entretanto, a escassez de recursos humanos não possibilita a assistência intensiva contínua e constante, por longos períodos de tempo. O berçário $D$ é o mais completo em suas instalações, dispondo de equipamento e instrumental compatíveis com as recomendações para um nível de atenção de maior complexidade ${ }^{6,7,8}$.

O uso de tecnologias e instrumental altamente sofisticados e de altos custos influencia a organização do trabalho nesse último berçário, havendo um serviço de manutenção com pessoal técnico de apoio e um grande envolvimento da enfermagem no controle e conservação dos materiais. Os cuidados com material e equipamento são reforçados nas passagens de plantão e reuniões. Por outro lado, percebemos queixas das enfermeiras quanto ao funcionamento de determinados equipamentos, sendo alguns subutilizados devido a defeitos no sistema eletrônico. Aspectos dessa natureza são freqüentemente discutidos nas políticas nacionais de ciência e tecnologia; a implantação de tecnologias de primeiro mundo esbarra em recursos humanos não preparados para sua manutenção e uso, ameaçando a plenitude de sua eficiência.

Em 1986 e 1987, a ação estratégica da Previdência Social contemplou essas questões, apresentando, pela primeira vez, uma política explícita em âmbito federal. Foi proposto a implantação de regionais de manutenção que trariam maior facilidade de assistência técnica e redução no custo operacional por unidade de serviço ${ }^{12}$. Tal sistemática urge ser viabilizada em larga escala. E imprescindível, também, o preparo do pessoal de enfermagem para o uso e conservação, de forma adequada, 
do instrumental envolvido na assistência de alta complexidade. Para tanto, é importante que as instituições formadoras de recursos reflitam sobre o seu papel na capacitação de pessoal, acompanhando a velocidade do desenvolvimento tecnológico.

Quanto aos recursos humanos predomina a polarização em dois agentes: o médico e o atendente de enfermagem que é uma categoria sem formação específica em enfermagem e com escolaridade muito variável. Essa conformação também foi encontrada em âmbito nacional pelo COFEn/ABEn ${ }^{13}$, sendo a situação preocupante, pois a Lei do Exercício Profissional de Enfermagem vigente estabelece a extinção da categoria atendente até $1996^{14}$. A profissionalização das categorias de nível elementar da área de saúde faz parte da política de desenvolvimento de recursos humanos definida pelo SUDS, orientada pelo projeto "Larga Escala" com o objetivo de melhorar a qualidade da assistência prestada. Em razão dos dados encontrados, questionamos a operacionalização desse projeto e a absorção de auxiliares de enfermagem pelo mercado de trabalho. São necessários estudos avaliativos e estratégias para garantirem a sua implantação de forma contínua, permanecendo ainda, o problema da fiscalização efetiva nas instituições de saúde para controlar o preparo formal do pessoal admitido na enfermagem e sua educação continuada. A mão de obra sem preparo formal é sempre mais barata que a qualificada. Como os hospitais públicos trabalham com deficiência de verbas e recursos e os privados visam o lucro, a possibilidade de elevarem seus custos, admitindo pessoal de enfermagem com melhor qualificação profissional e conseqüentemente melhores salários é muito remota.

A organização do trabalho mostra-se diferenciada de acordo com o pode e complexidade do hospital, confirmando o primeiro pressuposto teórico. Instituições de maior porte que prestam assistência mais especializada apresentam maior diversidade de agentes, um trabalho mais burocratizado e hierarquizado, sistema de informação mais complexo e procedimentos mais padronizados, mediados por rotinas escritas, aparelhos sofisticados e pelo conhecimento mais atualizado na área. Tais características acentuam-se nas instituições com finalidade de ensino e pesquisa. Aumentando a complexidade da instituição modificam-se as relações sociais, prioriza-se a qualificação profissional e a habilidade de operação e manutenção do instrumental médico-hospitalar.

No berçário $A$, o médico sem formação específica na área de pediatria e a atendente assistem a gestante, parto e recém-nascido. Há entre eles definição clara de papéis; a comunicação é mais verbal do que escrita. O trabalho não é fragmentado em tarefas: a atendente é a única assistente, realizando inclusive o preparo de fórmulas lácteas; o mesmo médico realiza a assistência à mãe e ao neonato de baixo risco, do nascimento à alta.
Como não há especialistas, existe a possibilidade do binômio mãe-filho receber uma assistência menos fragmentada, em que pesem as críticas possíveis referentes à competência específica no exercício de cada especialidade. Os procedimentos são rotinizados, porém não há normas escritas. $\mathrm{O}$ atendimento realizado pode ser caracterizado, em linhas gerais, no nível 1 de cuidado $^{6,7,8}$

O corpo clínico dos berçários B e C é constituído por pediatras com experiência em neonatologia. No $\mathrm{B}$, um pediatra assume a coordenação administrativa da unidade e todos assistem os seus clientes desde o nascimento até a alta hospitalar. As clientes particulares, ainda durante o processo de gestação, geralmente escolhem o pediatra, enquanto que as conveniadas são atendidas pelo plantonista escalado. No berçário $\mathrm{C}$, a divisão do trabalho é maior: um pediatra responsabiliza-se pela coordenação administrativa da unidade; outro, pela área acadêmica e todos assessoram os residentes, constituindo um corpo clínico mais complexo. Clientes particulares ou com convênios diferenciados são assistidos do nascimento a alta pelo mesmo pediatra, escolhido pela gestante ou escalado no plantão; os demais são atendidos pelos residentes. Dispondo de serviços de apoio especializados, esse corpo clínico executa cuidados intensivos neonatais, embora com algumas limitações nas instalações físicas e contando apenas com atendentes na enfermagem.

$O$ berçário $D$ possui pediatras docentes e contratados, com diferentes níveis de formação, especialistas na atenção neonatal e residentes. Quando necessário, profissionais de outras especialidades são envolvidos na assistência. Há uma divisão maior do trabalho, cabendo ao docente desenvolver as atividades administrativas e de ensino. A divisão hierárquica entre os residentes é determinada pelo nível de risco da criança e tempo de residência. Durante as 24 horas do dia, há pelo menos três médicos na unidade. O trabalho é fragmentado havendo escala de atividades e de plantão; há sistema de informação e registros mais complexos e burocratizados. A assistência realizada corresponde ao nível III, ${ }^{6,7,8}$ sendo centro de referência terciária regional.

A assistência de enfermagem nas unidades B e $C$ é realizada basicamente por atendentes, orientada e supervisionada, em raros momentos, pela enfermeira que não é exclusiva do berçário, executando atividades administrativas e controle das atendentes. Não há fragmentação em tarefas, pois a atendente é a única assistente em cada plantão. Atividades que requerem maior elaboração, como registros e controle de materiais, são realizadas por aquelas com melhor escolaridade e maior tempo de serviço.

O berçário $D$ dispõe de reduzido número de atendentes e maior quantidade de auxiliares e enfermeiras, trabalhando exclusivamente na unidade neonatal. Existe uma estrutura hierarquizada com cargos e funções 
diferenciados. Na divisão técnica do trabalho atribuise às atendentes e auxiliares, as atividades manuais de cuidado direto, sendo que as primeiras executam procedimentos mais simples, enquanto as auxiliares administram as medicações e assistem crianças com cuidados mais complexos. As enfermeiras ocupam cargos de chefia, realizam intervenções assistenciais de maior complexidade e risco, controle e supervisão dos subalternos e do próprio processo de trabalho. Parte das atividades burocráticas da unidade é delegada aos escriturários e agente administrativo. A estrutura organizacional da instituição, com grande número de rotinas de serviço e documentação, legitima a função de controle exercida pela enfermeira.

A supervisão é identificada como atividade executada no trabalho conjunto com os auxiliares e atendentes, conforme ilustram os relatos: “... Tem que trabalhar junto com as funcionárias, pois só assim conseguimos captar as coisas... Tem que supervisionar junto, fazendo atividades com elas, e não à distância, pois são diferentes estes dois tipos de supervisão..., tem que ficar de olho..." Embora, inicialmente, a enfermeira tente amenizar a relação de dominação sobre os funcionários, há ambigüidade na fala explicitando ao final a dimensão fiscalizadora de controle. Características semelhantes foram encontradas por MENDES GONÇALVES ${ }^{5}$ e ALMEIDA $^{15}$, na representação das enfermeiras sobre a supervisão, em Unidades Básicas de Saúde. Parece-nos que tais profissionais procuram negar as relações de poder/subordinação com os funcionários, atribuindo sentido pejorativo à atividade de controle, talvez por desconhecerem a sua importância dentro do trabalho coletivo ou por a compreenderem como um fim em si mesmo e, portanto, limitando-se em fiscalizar se o procedimento técnico foi ou não cumprido, perdendo de vista a finalidade do trabalho.

Não percebemos intervenções voltadas para a supervisão técnica do pediatra, possivelmente devido às dificuldades de uma prática que tem como ideologia a autonomia profissional, que é sustentada pela dominação do seu saber e da sua competência técnica na organização da divisão do trabalho ${ }^{5,16}$. As relações formais estruturadas

para permitir a supervisão sistemática do trabalho médico aparecem somente nos berçários envolvidos com a formação de recursos humanos (C eD), sendo direcionada aos residentes e acadêmicos e operacionalizada através da Visita Médica. É instrumentalizada pelo conhecimento da doença enquanto disfunção do corpo anátomofisiológico, embora, em muitos momentos, o recorte seja ampliado contemplando outros aspectos do processo saúdedoença, como os determinantes sócio-culturais e econômicos. O controle é feito por um sistema de informações e anotações e por rotinas de serviço escritas, especialmente no berçário D.
Devido a uma hierarquia institucionalizada, o médico faz direta ou indiretamente a supervisão e o controle das atividades realizadas pela enfermagem, apreendendo-se dois aspectos nesse processo: primeiro, ela se dá no relacionamento interpessoal, caracterizando-se como uma atividade desempenhada sempre individualmente e segundo, a supervisão se atém mais às tarefas parcelares decorrente da terapêutica, em especial ao cumprimento da prescrição.

As atividades administrativas realizadas pelos pediatras e enfermeiras são complementares. Os docentes do hospital-escola, ápices da hierarquia, controlam e supervisionam o processo de trabalho no berçário como um todo; as enfermeiras, instâncias intermediárias, assumem mais diretamente o controle e supervisão do pessoal de enfermagem, de outros funcionários e do ambiente, tomando para si a responsabilidade de fazerem cumprir as normas e regulamentos da instituição. Nessa divisão complexa de funções, há uma relativa autonomia do médico e da enfermeira, sendo maior a do médico porque responde pelo diagnóstico e terapêutica.

$\mathrm{Na}$ assistência, o trabalho de enfermagem envolve o cumprimento da prescrição, higienização, alimentação, controle de ingesta e eliminações, termorregulação, profilaxia de infecção, antropometria e observação de sinais de alarme. No cuidado intensivo os procedimentos são mais complexos, instrumentalizados pelas técnicas de enfermagem específicas para as diversas terapias e mediados por equipamentos sofisticados, que tanto fazem o controle de disfunções biológicas como necessitam ser controlados, constituindo-se ora em instrumentos ora em objetos de trabalho. A enfermagem também faz a mediação da inter-relação e comunicação do berçário com outros setores do hospital e transmite normas informais de serviço à clientela e agentes.

Quanto à sistemática de prestação de cuidados neonatais, a enfermagem depara-se no alojamento conjunto com uma situação de atendimento ampliado para o binômio, onde a mãe é co-participante da assistência ao filho. Entretanto, a simples implantação do sistema sem que os agentes tenham um conhecimento específico sobre a relação mãe-filho para instrumentalizar suas ações, não assegura o alcance dos resultados esperados.

Constatamos organizações diferentes do trabalho nos berçários $C$ e $D$ que têm este sistema implantado de maneira intermitente e contínua, respectivamente. Na unidade C a interação mais íntima do binômio é possibilitada espontaneamente, apoiando-se a amamentação materna em esquema de livre demanda. Por outro lado, não observamos ações educativas sistematizadas, a orientação dependia das peculiaridades das atendentes, sendo que a maioria apresentou um trabalho normativo, mecanizado, inespecífico e de certa forma até autoritário. A assistência à puérpera e ao 
neonato é ministrada em separado, respectivamente pelas atendentes da obstetrícia e berçário, havendo uma diluição das responsabilidades e uma divisão do trabalho pouco definida durante o aleitamento materno, evidenciando-se superposição de papéis e conflitos. Embora o discurso sobre o alojamento conjunto acene como principal vantagem o atendimento integral às necessidades do binômio mãe-filho, observamos aí a fragmentação do cuidado, restrito à manutenção das funções orgânicas dos assistidos, medicalizando os fenômenos fisiológicos da maternidade.

Inadequações e deficiências nas atitudes e capacidades dos profissionais de saúde no contato com as puérperas e famílias também foram encontradas por MORENO et ai ${ }^{7}$, em serviços da América Latina. Na avaliação geral dos recursos humanos, estas deficiências foram mais enfatizadas do que os aspectos quantitativos e de conhecimentos técnicos específicos.

Já na unidade D ocorrem intervenções educativas sistematizadas; as atendentes e auxiliares da obstetrícia fazem orientações individuais ou para grupos de puérperas, ensinando os cuidados básicos com o neonato e supervisionando-as, posteriormente, na realização de procedimentos como o banho, curativo umbilical e aleitamento materno. A comunicação com a clientela é direta e informal, mas na dinâmica o trabalho caracteriza-se como normativo. Há também ações educativas em grupo realizadas pelas enfermeiras que orientam e incentivam 0 aleitamento materno, o autocuidado com a mama puerperal e os cuidados com o recém-nascido.

A enfermeira do berçário ainda desenvolve um programa de treinamento para mães de prematuros. As orientações, sobre cuidados básicos e especiais são individuais, iniciando-se quando a criança apresenta condições para alta, definidas por parâmetros biológicos e deliberada na Visita Médica. A enfermeira avalia a necessidade do envolvimento de outros profissionais como assistente social, enfermagem de saúde pública e do banco de leite. Percebemos, aí, que o processo terapêutico centrado nas evidências clínicas e na patologia amplia-se, havendo um esforço na busca da compreensão contextualizada das dimensões psicológicas, sócio-econômicas, culturais e ambientais. O objeto de trabalho, que em princípio estava centrado no recém-nascido, é ampliado diante da perspectiva de alta hospitalar, envolvendo a puérpera e família. Para responder às necessidades que se apresentam, são acionados embasamentos teóricos advindos da epidemiologia, psicologia, sociologia, antropologia e educação.

Pelo exposto do trabalho em berçários, verificamos que, de maneira geral, o objeto de ação está centrado na criança e nos casos mais complexos prioriza-se a patologia, os sinais e sintomas, dentro da assistência clínica, individual e curativa. Percebemos, entretanto, algumas ações mais amplas, apreendendo o binômio mãe-filho e família, ampliando o nosso terceiro pressuposto teórico, isto é, o objeto de ação das práticas de saúde em berçário é o corpo anátomobiológico do neonato em suas relações com a mãe e a família na adaptação à vida extra-uterina.

Especificamente sobre o trabalho da enfermeira, resumimos dois grupos de atividades: assistenciais e gerenciais. Nos berçários B e C, o trabalho da enfermeira caracteriza-se principalmente pela execução de atividades gerenciais de organização, coordenação e articulação do trabalho de enfermagem e deste com as outras práticas, conforme o encontrado por ALMEIDA ${ }^{15}$ em unidades básicas de saúde. Entretanto, na unidade de maior nível de complexidade, as enfermeiras, exclusivas do berçário, envolvem-se também com o cuidado direto, realizando procedimentos técnicos e orientações, demonstrando ter conhecimento sobre a condição de cada neonato e participando da Visita Médica.

No trabalho médico, o processo de diagnose e a terapêutica constituem-se em elementos nucleares. O processo de avaliação clínica inicia-se pela anamnese, através da qual colhem-se dados maternofetais relevantes para a saúde da criança; é seguida do exame físico, onde buscam-se sinais compatíveis com situações de normalidade, de risco ou patologia. Após estas duas etapas, se os dados caracterizarem uma condição clínica de normalidade, faz-se a prescrição médica, cujo conteúdo, nos três berçários de menor nível de complexidade, aborda sobre o aleitamento natural e procedimentos rotineiros. Diante de situações de risco ou patológica, se necessário, solicita-se a realização de exames complementares e avaliação de especialistas, cujos resultados adicionados ao quadro clínico refutam ou confirmam a hipótese diagnóstica inicial, culminando na prescrição medicamentosa profilática ou curativa para cada situação específica. A colheita de exames é feita em maior quantidade e de maneira sistemática no berçário $D$. Todo o processo é registrado na evolução clínica, sendo dinâmico e contínuo, buscando-se como produto final a manutenção das condições de vitalidade, a cura da doença ou o controle da situação de risco neonatal.

$\mathrm{Em}$ todos os berçários, os neonatos submeteram-se à pelo menos uma avaliação clínica diária, tornando-se mais freqüente a medida da necessidade, em especial naqueles com cuidado intensivo. A técnica e duração do exame físico variam com a condição clínica da criança, tempo de nascimento, experiência do profissional e interação com a puérpera.

Em síntese, confirmando o segundo pressuposto teórico, constata-se uma divisão do trabalho, onde os médicos concebem o diagnóstico e decidem a terapêutica e, portanto, detêm a racionalidade que orienta a assistência; 
a enfermagem executa atividades auxiliares e complementares ao ato médico, como o cuidado direto e o controle do ambiente. A enfermagem é subordinada ao médico, pois a natureza de seu trabalho é definida a partir do trabalho médico e a posição funcional das suas tarefas determina-se a partir da centralidade das tarefas médicas, conforme já assinalou ALMEIDA ${ }^{15}$ e CARAPINHEIRO ${ }^{16}$, entre outros.

Quanto às medidas para controle de infecção em berçários, a lavagem das mãos constitui procedimento freqüentemente encontrado, havendo variações técnicas, que fogem às normas preconizadas. O mesmo acontece com o espaçamento entre os berços e desinfecção do ambiente e utensílios. O berçário $D$ apresenta maior rigor nas medidas de controle de infecção, havendo normas escritas, orientações dos agentes nas reuniões de grupo e em passagens de plantão e uma Comissão de Infecção Hospitalar, que realiza pesquisa do foco infeccioso ao detectarem evidências de surtos.

Em termos gerais, observamos que as finalidades do trabalho em berçário confirmam o quarto pressuposto teórico. Entretanto, o trabalho está organizado de diferentes formas e o nível de atenção é resultante de uma complexa combinação dos recursos humanos e materiais, área física, procedimentos realizados, sistemas de apoio, programação e administração do serviço.

Sob o prisma da regionalização, os berçários $A, B$ e $C$ integram serviços de atenção secundária; o $D$ é de referência terciária. Todavia, a realidade apresentada é heterogênea, os serviços não refletem integralmente os três níveis de cuidado definidos pelo Comitê de Saúde Perinatal, Academia Americana de Pediatria e Secretaria de Estado da Saúde de São Paulo, dificultando uma classificação única para cada unidade. Não há um padrão para as instalações, recursos humanos, materiais e organização do trabalho, divergindo as relações entre os agentes e destes com a clientela, de modo que unidades supostamente classificadas dentro de um mesmo nível de cuidado apresentam recursos e práticas diferentes, além de administrar cuidados em mais de um nível. Devido às dificuldades operacionais mencionadas, não fizemos uma classificação dos berçários por nível de atendimento, optando-se por descrever suas características gerais.

\section{CONSIDERAÇÕES FINAIS}

A análise empreendida permitiu-nos confirmar a maioria dos pressupostos teóricos e dimensionar a organização do trabalho em diferentes berçários, cujos dados poderão servir de subsídios para a reorganização regional da atenção perinatal. Observamos algumas deficiências quanto às instalações, recursos materiais, tecnológicos e humanos, em especial de enfermagem.

Nos berçários de menor complexidade, predominam os atendentes de enfermagem realizando a assistência ao recém-nascido. Acreditamos que eles devam ser preparados formalmente, através de cursos de auxiliares de enfermagem, para realizarem essa assistência, além de receberem formação especializada sobre conhecimentos de psicologia neonatal familiar e técnicas educativas, a fim de desenvolverem habilidades para interagirem com o binômio mãe-filho e família. No berçário mais complexo, a enfermagem é constituída de três categorias (atendentes, auxiliares e enfermeira) e auxiliada por agentes administrativos, sendo o processo de trabalho fragmentado em tarefas.

A reorganização da assistência ao parto hospitalar é necessária para atender a demanda que vem pressionando pela expansão de cobertura e qualidade de atendimento. A solução não seria o aumento do número de maternidades e berçários, mas sim o estabelecimento de uma política para corrigir e fortalecer os serviços existentes. As notáveis diferenças na mortalidade neonatal não se explicam pela maior ou menor disponibilidade de alta tecnologia, mas sim pela maneira como se organizam os recursos e pelas atitudes dos profissionais frente à comunidade.

É oportuno destacar a questão do financiamento da atenção perinatal, pois a assistência em terapia intensiva apresenta custos elevados. No processo de reorganização do sistema de saúde, propôs-se a reordenação dos serviços médico-hospitalares de alto custo através do estabelecimento de centros de referência, públicos, cabendo ao Estado o provimento desta assistência através do repasse de recursos aos hospitais $^{12}$. Devido às dificuldades políticas e econômicas na sistemática de transferência de recursos do setor saúde, os hospitais públicos freqüentemente encontramse com limitações orçamentárias.

Os resultados encontrados possibilitaram apreender que a proposta da rede regionalizada e hierarquizada não está efetivamente implantada nos serviços de atenção perinatal da regional de saúde de Ribeirão Preto, registrando-se ociosidade na ocupação dos berços de algumas unidades neonatais e sobrecarga no berçário do hospital-escola. Não há um diagnóstico dos recursos e capacidades dos berçários, um fluxograma de referência e contra-referência e uma articulação das maternidades com a rede básica de saúde a fim de assegurar a continuidade da assistência pré e pós-natal. As estatísticas regionais, onde as causas perinatais contribuem substancialmente para a mortalidade infantil, reforçam a necessidade de se estabelecer uma política de desenvolvimento desta assistência e uma organização tecnológica do trabalho eficiente. Urge portanto, a elaboração de um projeto visando a otimização dos serviços e a implantação do sistema regional de cuidados perinatais, tendo como finalidade última a redução da mortalidade, de modo que as mortes evitadas correspondam a uma boa qualidade de vida. 


\section{THE ORGANIZATION OF NEWBORN CARE IN NURSERIES IN THE REGION OF RIBEIRÃO PRETO-SP, BRASIL-1992}

The present study analyses the organization of newborn care in different nurseries in the region of Ribeirão Preto as well as how nursing participates in this work. Through observation and interviews in 4 nurseries, we found that the work organization varies according to the hospital size and complexity. Action is centered on the child and in more complex cases; priority is given to the pathology and clinical care. We also observe enlarged actions, involving the binomial mother-child and the family. The quality of care is a result of a complex combination of human resources, material and installation. Bigger and more complex institutions present a diversity of personnel, more bureaucracy and hierarchy, information and technology system, routine procedures by written norms and more sophisticated equipment. The object of action is centered on the child, but there are practices in which the object is enlarged to the binomial mother-child and the family.

KEY WORDS: Neonatal care, nurseries, neonatal nursing

\section{LA ORGANIZACIÓN DEL TRABAJO EN LA ASISTENCIA AL RECIÉN-NACIDO EN GUARDERÍAS DE LA REGIÓN DE RIBEIRÃO PRETO-SP. BRASIL-1992}

Las autoras analizaron la organización de la asistencia al recién-nacido en guarderías de la región de Ribeirão Preto y cómo la enfermería participa de este trabajo. A través de observación y citas en cuatro guarderías, las autoras constataron que la organización del trabajo se diferencia por el porte y complejidad del hospital. La acción está centrada en el niño en casos mas complejos se privilegia la patología y la asistencia clínica. Percibieron también algunas acciones más amplias, aprehendiendo el binomio madre-niño y la familla. El nivel de la atención es el resultado de una compleja combinación de los recursos humanos, materiales e instalaciones. La institución de mayor porte y complejidad presenta diversidad de agentes, trabajo más burocratizado y jerarquizado, sistema de información y tecnología complejas, procedimientos rutinarios mediados por normas escritas y aparatos sofisticados. El objeto de acción está centrado en el niño, todavía hay prácticas cuyo objeto es ampliado para el binomio madre-niño y familiares.

TÉRMINOS CLAVES: asistencia neonatal, guarderías, enfermería neonatal

\section{REFERÊNCIAS BIBLIOGRÁFICAS}

01. ORGANIZACIÓN PANAMERICANA DE LA SALUD/ORGANIZACIÓN MUNDIAL DE LA SALUD. Las condiciones de salud en las Américas. Washington, 1990. v. 1 e 2. (Publicación Científica, n. 524).

02. RIBEIRÃO PRETO. Secretaria Municipal da Saúde. Sistema de coleta e análise de estatísticas vitais de Ribeirão Preto - SICAEV dados 70 a 90 e 1991. Ribeirão Preto: Núcleo de Informática, 1992.

03. Plano de saúde para Ribeirão Preto. Ribeirão Preto, 1989. /mimeografado/

04. Plano diretor de saúde do município de Ribeirão Preto. Ribeirão Preto: Comissão Interinstitucional Municipal de Saúde, 1990.

05. MENDES GONÇALVES, R.B. Tecnologia e organização social das práticas de saúde: características tecnológicas do processo de trabalho na rede estadual de centros de saúde em São Paulo. São Paulo: Hucitec/Abrasco, 1994.
06. AMERICAN ACADEMY OF PEDIATRICS. Standards and recommendations for hospital care of newborn infants. 6.ed. Illinois, 1977.

07. SÃO PAULO (Estado). Secretaria de Estado da Saúde. Recomendações para padronização da assistência hospitalar ao recém-nascido. Diário Oficial do Estado, São Paulo, 02 abr. 1981. Seção 1, 91(063).

08. BRASIL. Ministério da Saúde. Secretaria Nacional de Ações de Saúde. Coordenadoria de Saúde Materno Infantil. Programa de assistência a saúde perinatal: bases programáticas. Brasília, 1991.

09. BRASIL. Ministério da Saúde. Terminologia básica em saúde. 2.ed. Brasília: Centro de Documentação, 1985. (Série B. Textos Básicos em Saúde, 8).

10. ORGANIZAÇÃO PAN-AMERICANA DE SAÚDE/ ORGANIZAÇÃO MUNDIAL DE SAÚDE. Condições de eficiência dos serviços de atenção materno-infantil. Washington, 1987.

11. MINAYO, M.C.S. O desafio do conhecimento: pesquisa qualitativa em saúde. 3.ed. São Paulo: Hucitec/Abrasco, 1994. 
12. CORDEIRO, H. Sistema único de saúde. Rio de Janeiro: Yurí, 1991.

13. CONSELHO FEDERAL DE ENFERMAGEM/ ASSOCIAÇÃO BRASILEIRA DE

ENFERMAGEM. O exercício da enfermagem nas instituições de saúde do Brasil: 1982/1983 - Força de trabalho em enfermagem. Rio de Janeiro, 1985. v.1.

14. BRASIL. Leis etc. Lei n. 7.498 de 25 de junho de 1986. Dispõe sobre a regulamentação do exercício de enfermagem. Diário Oficial da União, Brasília, 26 jun. 1986. Seção 1, p. 2735 .
15. ALMEIDA, M.C.P.; MELLO, D.F. O trabalho de enfermagem e sua articulação com o processo de trabalho em saúde coletiva: rede básica de saúde em Ribeirão Preto. Rev. Bras. Enfermagem, v.44, n.213, p.64-75, 1991.

16. CARAPINHELRO, G. Saberes e poderes no hospital: uma sociologia dos serviços hospitalares. Lisboa: Edições Afrontamento, 1993.

17. MORENO, E.M. et al. Evaluación de servicios de salud materno infantil: condiciones de eficiencia en países de América Latina, 1985 - 1987. Caraballeda: OPAS/OMS, 1987. (Documento preparado para el taller Regional sobre Evaluación de Servicios de Salud Materno infantil). 
QUADRO I - Características dos berçários observados de acordo com sua classificação, número de leitos e nascimentos, planta física e recursos humanos

\begin{tabular}{|c|c|c|c|c|}
\hline & A & B & C & D \\
\hline $\begin{array}{l}\text { CLASSIFICAÇÃO } \\
\text { DOS HOSPITAIS }\end{array}$ & $\begin{array}{l}\text { - GERAL } \\
\text { - MONOBLOCO } \\
\text { - PRIVADO } \\
\text { FILANTRÓPICO }\end{array}$ & $\begin{array}{l}\text { COM ESPECIALI- } \\
\text { DADE } \\
\text { - PAVILHONAR } \\
\text { - PRIVADO LUCRA- } \\
\text { TIVO }\end{array}$ & $\begin{array}{l}\text { COM ESPECIALI- } \\
\text { DADES } \\
\text { - MULTIBLOCO } \\
\text { - PRIVADO } \\
\text { BENEFICENTE } \\
\text { - AUXILIAR DE } \\
\text { ENSINO }\end{array}$ & $\begin{array}{l}\text { COM ESPECIA- } \\
\text { LIDADES } \\
\text { - MULTIBLOCO } \\
\text { - PÚBLICO } \\
\text { - UNIVERSITÁRIO }\end{array}$ \\
\hline $\mathrm{N}^{\circ}$ DE LEITOS & 06 & 18 & 14 & $\begin{array}{l}21 \text { NO BERÇÁRIO } \\
23 \text { NO ALOJA- } \\
\text { MENTO CONJUNTO }\end{array}$ \\
\hline $\begin{array}{c}\text { NASCIMENTOS } \\
(\text { ANO 1991) }\end{array}$ & 247 & 205 & 1092 & 2865 \\
\hline PLANTA FÍSICA & $\begin{array}{l}\text { - ENFERMARIA } \\
\text { ÚNICA }\end{array}$ & $\begin{array}{l}\text { - ANTE SALA } \\
\text { - SALA DE PROCEDI- } \\
\text { MENTO } \\
\text { - NORMAIS } \\
\text { - BERÇÁRIO PREMA- } \\
\text { TUROS* } \\
\text { - BERÇÁRIO PATO- } \\
\text { LÓGICOS* }\end{array}$ & $\begin{array}{l}\text { - SALA DE PROCE- } \\
\text { DIMENTO } \\
\text { - NORMAIS E } \\
\text { PREMATUROS } \\
\text { - ISOLAMENTO } \\
\text { - ALOJAMENTO } \\
\text { CONJUNTO } \\
\text { - UTIN** }\end{array}$ & $\begin{array}{l}\text { - ANTE SALA E } \\
\text { POSTO } \\
\text { - NORMAIS E } \\
\text { PREMATUROS } \\
\text { - ISOLAMENTO } \\
\text { - ALOJAMENTO } \\
\text { CONJUNTO } \\
\text { - UTIN** }\end{array}$ \\
\hline $\begin{array}{l}\text { RECURSOS } \\
\text { HUMANOS }\end{array}$ & $\begin{array}{l}4 \text { MÉDICOS } \\
6 \text { ATENDENTES }\end{array}$ & $\begin{array}{l}5 \text { PEDIATRAS } \\
1 \text { ENFERMEIRA*** } \\
5 \text { ATENDENTES }\end{array}$ & $\begin{array}{l}4 \text { PEDIATRAS } \\
\text { EFETIVOS } \\
1 \text { PEDIATRA } \\
\text { AUXILIAR } \\
3 \text { RESIDENTES } \\
4 \text { ENFERMEI- } \\
\text { RAS*** } \\
6 \text { ATENDENTES }\end{array}$ & $\begin{array}{l}5 \text { PEDIATRAS } \\
\text { DOCENTES } \\
15 \text { PEDIATRAS*** } \\
\text { CONTRATADOS } \\
52 \text { RESIDENTES*** } \\
6 \text { ENFERMEIRAS } \\
19 \text { AUXILIARES } \\
5 \text { ATENDENTES } \\
\text { ESCRITURÁRIAS } \\
\text { AG. ADMINIST. } \\
\text { ACADÊMICOS }\end{array}$ \\
\hline
\end{tabular}

* Unidades desativadas

** Unidades da Terapia Intensiva Neonatal

*** Pessoal não fixo no berçário (atua em outras enfermarias e ambulatórios) 